\title{
W Local difference of characteristics of patients with out-of-hospital cardiac arrest
}

1 Hazuki Koguchi ${ }^{1}$, Wataru Takayama ${ }^{1,2}$, Kanae Ochiai ${ }^{2}$, Kiyoshi Murata $^{1}$, Yasuhiro Otomo ${ }^{2}$

${ }^{1}$ The Shock Trauma and Emergency Medical Centre, Matsudo City Hospital, Chiba, Japan

${ }^{2}$ Trauma and Acute Critical Care Medical Centre, Tokyo Medical and Dental University, Tokyo, Japan

Introduction

- Some reports said that out-of-hospital cardiac arrest (OHCA) in urban or rural settings associated with survival to discharge, but few reports compared the local difference in particular.

- We studied the characteristics of OHCA patients transported to hospitals in an urban and a suburb setting.

\section{Method}

- Retrospective cohort study of non-traumatic OHCA patients in two emergency medical centres; Tokyo Medical and Dental University Medical Hospital (urban) and Matsudo City Hospital (suburb) from April 2013 to August 2016.

- Multivariate analysis of risk factors for survival to discharge.
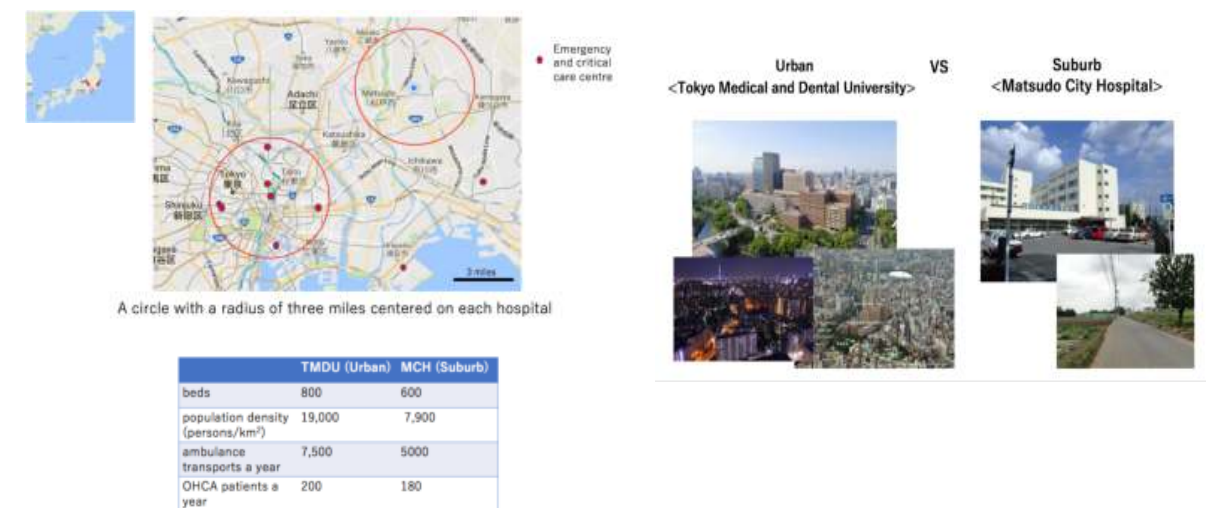

\begin{tabular}{|c|c|c|c|}
\hline & $\begin{array}{l}\text { Urban, } \\
n=469\end{array}$ & $\begin{array}{l}\text { Suburb, } \\
n=472\end{array}$ & p value \\
\hline Age (SD) & $65.2(17.8)$ & $71.9(15.3)$ & $<0.001$ \\
\hline Female, $n(\%)$ & $134(28.6)$ & $181(38.3)$ & 0.002 \\
\hline Witness, n (\%) & $201(42.9)$ & $180(38.1)$ & 0.15 \\
\hline Bystander, $n(\%)$ & $100(21.3)$ & $204(43.2)$ & $<0.001$ \\
\hline Shockable initial wave, $n(\%)$ & $64(13.6)$ & $61(12.9)$ & 0.77 \\
\hline Transport times, $\min (\mathrm{SD})$ & $28.6(8.9)$ & $24.2(10.4)$ & $<0.001$ \\
\hline ROSC, $n(\%)$ & $134(28.6)$ & $204(43.2)$ & $<0.001$ \\
\hline Survival to discharge, $n$ (\%) & $14(3.0)$ & $40(8.5)$ & $<0.001$ \\
\hline
\end{tabular}

Characteristics in each area

Discussion

- People in an urban area do not like concern with other people. - Higher buildings, narrow roads, heavy traffic volume were also involving in this result.

Conclusion

- The quality of resuscitation did not differ both in an urban and a suburb setting.

- There were local differences in out-of-hospital factors such as bystander CPR and ambulance transport times, and we would have to improve emergency medical systems and inform people about the importance of prehospital resuscitation. 